\title{
Inhibition of p53 sensitizes MCF-7 cells to ceramide treatment
}

\author{
AMANDA P. STRUCKHOFF ${ }^{1}$, BHUMI PATEL ${ }^{2}$ and BARBARA S. BECKMAN ${ }^{2}$ \\ ${ }^{1}$ Department of Pharmacology and Experimental Therapeutics, LSU Health Sciences Center, New Orleans, LA 70112; \\ ${ }^{2}$ Department of Pharmacology, Tulane University Health Sciences Center, New Orleans, LA 70112, USA
}

Received January 26, 2010; Accepted March 5, 2010

DOI: 10.3892/ijo_00000649

\begin{abstract}
Ceramide signaling plays an important role in tumor progression and development of chemoresistance, and ceramide-based therapies are proposed as potential therapeutic tools for the treatment of breast cancer. We investigated the effect of exogenous ceramide on the cell cycle progression of MCF-7 breast cancer cells. Ceramide induced a selective arrest of MCF-7 cells in the $\mathrm{G}_{1}$-phase, which was associated with a decreased expression of cyclins $\mathrm{D}$ and $\mathrm{E}$ and increased expression of p53 and p21. Interestingly, inhibition of p53 using pifithrin $\alpha$ or RNAi sensitized MCF-7 cells to ceramide-induced cell death. DNA content analysis suggested that sensitization of cells was due to an increased induction of apoptosis in MCF-7 cells. The increased sensitivity to ceramide, in the context of p53 inhibition, may be due to decreased expression of $\mathrm{p} 21$, as siRNA targeted to p21 also sensitized MCF-7 cells to ceramide-induced death. These data demonstrate that in tumors with inactivating mutations of p53, ceramide-based therapies might provide a novel and effective treatment option.
\end{abstract}

\section{Introduction}

While known to be a constituent of cell membranes for years, ceramide was first identified in 1988 by Kolesnick et al as a lipid signaling intermediate, similar to diacylglycerol (1). It has since been demonstrated that generation of ceramide is a common cellular response following exposure to a diverse array of growth-suppressive agents, including most clinically used chemotherapeutic drugs (2-5). Following drug exposure,

Correspondence to: Dr Barbara S. Beckman, Department of Pharmacology, Tulane Health Sciences Center, 1430 Tulane Avenue SL-83, New Orleans, LA 70112, USA

E-mail: bbeckman@tulane.edu

Abbreviations: Cer, $\mathrm{C}_{8}$-ceramide; $\mathrm{DH}-\mathrm{Cer}, \mathrm{C}_{8}$-dihydroceramide; PTH $\alpha$, pifithrin $\alpha$; MTT, 3-(4,5-dimethylthiazol-2-yl)-2,5-diphenyltetrazolium bromide; PI, propidium iodide; shRNA, short-hairpin RNAi; ROS, reactive oxygen species

Key words: ceramide, p53, cell cycle arrest, breast cancer the treatment-induced rise in ceramide is critical for response to the therapeutic agent, and pharmacologic manipulation of ceramide production or accumulation can alter the response to therapy $(6,7)$. In addition, in certain cell types, treatment with exogenous ceramide can cause cell death at concentrations similar to that produced by cells in response to cytotoxic agents (8).

Consistent with the principle that elevated intracellular ceramide contributes to tumor cell death during therapy, aberrant or decreased ceramide signaling has been implicated in contributing to resistance to cancer therapy. Many radiationresistant cell lines and isolated tumor specimens do not produce ceramide following irradiation (9-11) and a number of multidrug- and TNF $\alpha$-resistant cancer cell lines do not generate, or accumulate, ceramide in response to chemotherapy $(6,12-15)$. These data suggest that clinical manipulation of ceramide levels within tumors represents an important mechanism for decreasing both tumor survival and chemotherapeutic resistance mechanisms, and makes increasing ceramide signaling an attractive target for drug development.

p53 is a transcription factor that mediates cell cycle arrest and apoptosis, as well as DNA damage recognition and DNA repair, and inactivating mutations of p53 can contribute to the unregulated cell growth that frequently occurs in cancers. p53 accumulation commonly occurs following DNA damage, but has been demonstrated to occur following exposure to hypoxia as well as agents that cause inhibition of transcription or RNA metabolism (16). p53-mediated cell cycle arrest is associated with activation of $\mathrm{p} 21^{\text {Waf/Cip1 }}$ gene expression $(17,18)$, which leads to inhibition of cyclin E/CDK2 activity and inhibition of damaged cells at the $\mathrm{G}_{1}-\mathrm{S}$ checkpoint. p53 has been proposed as a determinant of drug sensitivity since mutations in p53 function have been correlated with a decreased response to chemotherapy and irradiation through a diminished capacity to undergo apoptosis in response to DNA damage following treatment $(19,20)$. However, others have demonstrated that the presence of wild-type p53 does not consistently predict the final response of tumors in vivo (21), and in some cases it appears that inactivation of p53 may sensitize cells to chemotherapeutic agents as the ability to induce growth arrest and subsequent DNA repair is lost (22-25).

Here we investigate the ability of exogenous ceramide to inhibit MCF-7 cell proliferation, and the role of p53 in mediating the ceramide-induced cellular response. We find that exogenous ceramide treatment prevents the progression of cells from the $G_{0} / G_{1}$-phase of the cell cycle and increases the 
expression of both $\mathrm{p} 53$ and $\mathrm{p} 21$. We propose that upregulation of p53 modulates the ability of ceramide to induce cell death, since in the context of p53 inhibition, breast cancer cells were sensitized to ceramide treatment. DNA analysis revealed that inhibition of p53 transcription and the resulting p21 expression decreased the population of cells arrested in the $\mathrm{G}_{1}$-phase, with a concomitant increase in the apoptotic cell fraction. These data may have important clinical implications since many breast cancer tumors are reported to contain inactivating mutations of $\mathrm{p} 53$.

\section{Materials and methods}

Cell culture. MCF-7 cells were grown in Dulbecco's modified Eagle's medium (DMEM) (Invitrogen, Carlsbad, CA) supplemented with $10 \%$ fetal calf serum (FCS), 1\% BME amino acids, MEM amino acids, sodium pyruvate, and penicillinstreptomycin (all from Life Technologies, Gaithersburg, MD). Cells were maintained in $75 \mathrm{~cm}^{2}$ tissue culture flasks (Sarstdt, Newton, $\mathrm{NC}$ ) in $37^{\circ} \mathrm{C}$ in a humidified atmosphere of $5 \% \mathrm{CO}_{2}$ and $95 \%$ air.

Reagents. D-erythro- $\mathrm{C}_{8}$-Ceramide (Cer), $\mathrm{C}_{8}$-dihydroceramide (DH-Cer), and pifithrin $\alpha$ (PTH) were purchased from Biomol (Plymouth Meeting, PA). Anti-p53 antibody was purchased from Upstate (Waltham, MA). Anti-cyclin $\mathrm{D}_{1}$ (1:500 dilution), cyclin $\mathrm{E}_{1}$ (1:500 dilution), cyclin $\mathrm{A}_{1}$ (1:500 dilution), and p21 (1:500 dilution) were all purchased from Santa Cruz (Santa Cruz, CA). The actin antibody (1:1000 dilution), 3-(4,5dimethylthiazol-2-yl)-2,5-diphenyltetrazolium bromide (MTT), RNase A, propidium iodide (PI), and dimethylformamide were purchased from Sigma (St. Louis, MO).

MTT viability assay. Viability of MCF-7 cells was determined as previously described (15). Briefly, MCF-7 cells were seeded in 96-well plates in phenol-free DMEM and allowed to adhere overnight. Cells were treated with the indicated agents for $24 \mathrm{~h}$. Following incubation time, $25 \mu \mathrm{l}$ MTT $(5 \mathrm{mg} / \mathrm{ml})$ was added for $4 \mathrm{~h}$, the cells were lysed with 20\% SDS in $50 \%$ dimethylformamide, and absorbances were read on an $\mathrm{EL}_{\mathrm{x}} 808$ Microtek plate reader (Winooski, VT) at $550 \mathrm{~nm}$, with a reference wavelength of $630 \mathrm{~nm}$. For siRNA studies, cells were plated as above and the following day the cells were transfected with either p21 siRNA or non-targeting, scrambled (control) siRNA (both from Santa Cruz) using Lipofectamine $2000^{\mathrm{TM}}$ (Invitrogen) at a siRNA: Lipofectamine 2000 at a ratio of 1:2 ( $\mathrm{vol} / \mathrm{vol})$. MCF-7 cells were transfected with siRNA for $30 \mathrm{~h}$ before treatment in order to ensure inhibition of target protein expression. For p53 siRNA viability studies, cells were plated as above and the following day the cells were transfected with either pSUPER empty vector or pSUPER expressing a short hairpin RNA sequence targeting the p53 gene (shRNA p53) (Oligoengine, Seattle, WA) using Lipofectamine 2000 transfection reagent (Invitrogen) at a siRNA: Lipofectamine 2000 at a ratio of 1:2 $(\mu \mathrm{g} / \mu \mathrm{l})$. MCF-7 cells were incubated with double-stranded siRNA or vectorsiRNA for $30 \mathrm{~h}$ before treatment in order to ensure sufficient inhibition of target protein expression using FuGENE 6' (Roche, Indianapolis, IN) in a ratio of 1:3 (wt:vol). MCF-7 cells were incubated for $24 \mathrm{~h}$ before treatment to ensure expression of construct. Cells were then treated as described above.

Western blot analysis. Analysis of protein expression was assessed as previously described (15). Briefly, $50 \mu \mathrm{g}$ of cell lysate was run on $12-15 \%$ SDS-PAGE gels, transferred to a nitrocellulose membrane (Bio-Rad, Hercules, CA), which was blocked with PBS-Tween (0.05\%)-5\% low-fat dry milk solution. The membranes were subsequently probed for the protein of interest by incubating them with the appropriate primary antibody at $4{ }^{\circ} \mathrm{C}$ overnight. The blots were then washed with PBS-Tween $(0.05 \%)$ solution and incubated with the appropriate secondary antibodies conjugated to horseradish peroxidase (1:10,000 dilution; Kirkegaard and Perry, Gaithersburg, MD). Immunoreactive proteins were detected using the ECL chemiluminescence system (Amersham, Arlington Heights, IL) and recorded by fluorography on Hyperfilm (Amersham), according to the manufacturer's instructions. Densitometry was performed using Quantity One 4.0 software (Bio-Rad) with all samples normalized to $\beta$-actin and all changes calculated as the fold-change over control.

Cell cycle analysis. Cells were plated at $7.5 \times 10^{6}$ cells per $100 \mathrm{~mm}^{2}$ dish in $10 \%$ DMEM. The following day, the medium was changed to serum-free DMEM for $24 \mathrm{~h}$ in order to synchronize the cells in $\mathrm{G}_{0} / \mathrm{G}_{1}$-phase. Following serumstarvation, medium was replaced with 5\% DMEM and treated as indicated. Cells were detached using 0.5\% EDTA-PBS, pelleted, resuspended in $0.5 \%$ glucose-PBS with a 22 -gauge needle. The samples were then fixed in $70 \%$ ethanol. The following day, samples were centrifuged, washed and RNase A and PI were added to the samples, for $45 \mathrm{~min}$ at $37^{\circ} \mathrm{C}$. DNA content was analyzed with a Becton-Dickinson FACStar flow cytometer measuring fluorescence emission at $638 \mathrm{~nm}$ for PI. The percentage of cells in each population of the cell cycle was determined using ModFit LT modeling software (Verity Software, Topsham, ME).

Semi-quantitative polymerase chain reaction. Total cellular RNA was isolated using TRIzol reagent (Invitrogen, Carlsbad, CA) or RNeasy Kit (Qiagen, Valencia, CA). Results from cDNA generated from RNA isolated from either TRIzol or RNeasy Kit did not differ. First-strand cDNA was synthesized from total RNA with Superscript II (Life Technologies, Rockville, MD, USA). Amplification reactions were performed using Platinum ${ }^{\circledR}$ PCR Supermix (Invitrogen). The primer sequences used for p53 (26), p21 Waf1/Cip (26), and HPRT (27) were previously described. Amplification was performed using a GeneAmp PCR System 9700 (PE Applied Biosystems, Foster City, CA) consisting of a 5-min denaturing step at $94^{\circ} \mathrm{C}$; followed by 30 cycles of $45 \mathrm{sec}$ at $94^{\circ} \mathrm{C}$; $45 \mathrm{sec}$ at either $50^{\circ} \mathrm{C}(\mathrm{p} 53)$ or $50^{\circ} \mathrm{C}(\mathrm{p} 21)$ or $50^{\circ} \mathrm{C}($ HPRT), and $1 \mathrm{~min}$ at $72^{\circ} \mathrm{C}$; followed by a final extension of $7 \mathrm{~min}$ at $72^{\circ} \mathrm{C}$. PCR products were separated by $2 \%$ agarose gel electrophoresis and were visualized with UV light with ethidium bromide staining. All samples were normalized to the PCR signal obtained for the housekeeping gene, HPRT (hypoxanthine phosphoribosyl transferase). Densitometry was performed using Quantity One 4.0 software with all samples normalized 


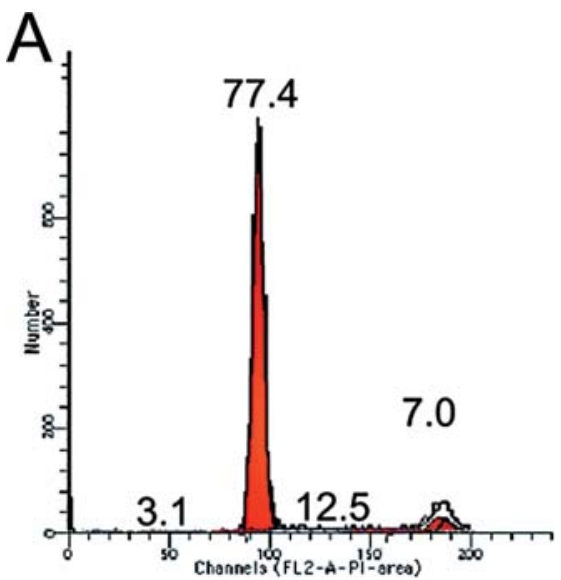

Figure 1. Exogenous ceramide induces a selective $\mathrm{G}_{0} / \mathrm{G}_{1}$-phase arrest followed by apoptosis. MCF-7 cells were plated at $1.5 \times 10^{6}$ cells per $75 \mathrm{~cm}^{2}$ and allowed to adhere overnight. The following day, culture medium was replaced with serum-free media for $24 \mathrm{~h}$ (A). The medium was then replaced with $10 \%$ DMEM with either vehicle (ethanol) or $30 \mu \mathrm{M}$ Cer for 18-36 h (B). The cells were harvested, fixed in $70 \%$ ethanol, stained with PI, and analyzed with FACS to determine DNA content. The percentage of cells in the apoptotic, sub- $\mathrm{G}_{1}$ (blue shaded region), $\mathrm{G}_{0} / \mathrm{G}_{1}$ (leftmost red region), $\mathrm{S}$ (hatched shaded region) or $\mathrm{G}_{2} / \mathrm{M}$ (rightmost shaded region) phase of the cell cycle was determined using ModFit Pro Analysis software, and are the average percentages from three separate experiments.

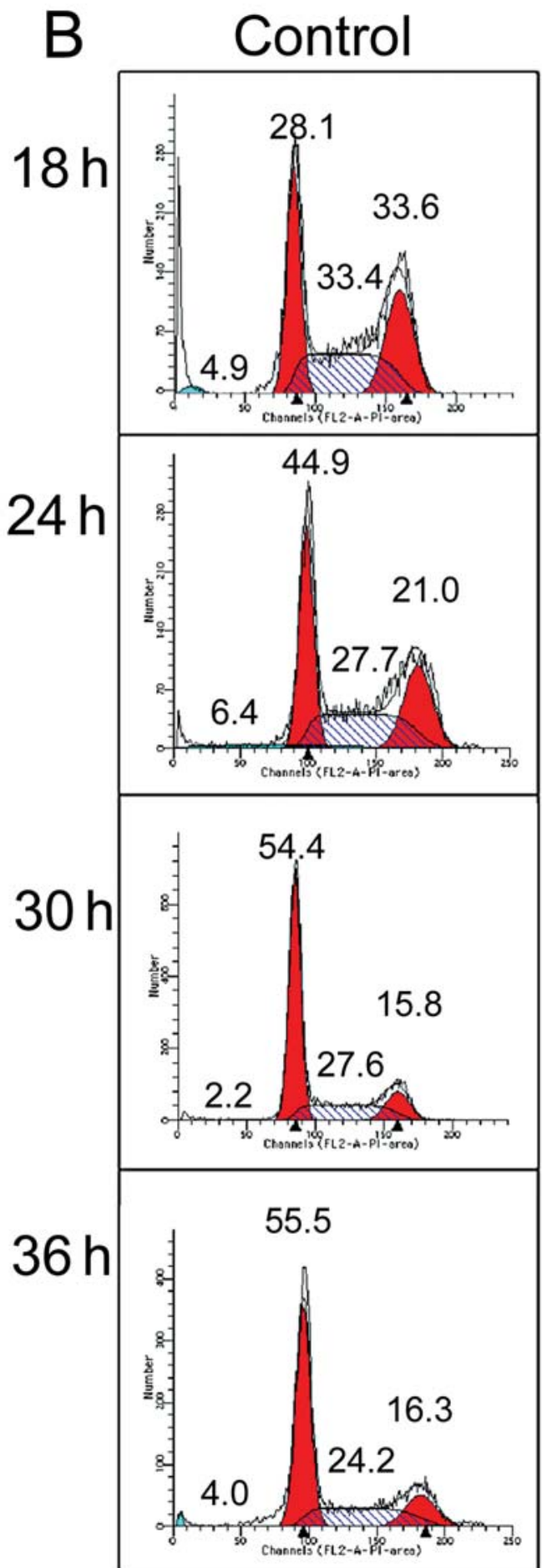

$30 \mu \mathrm{M}$ Cer

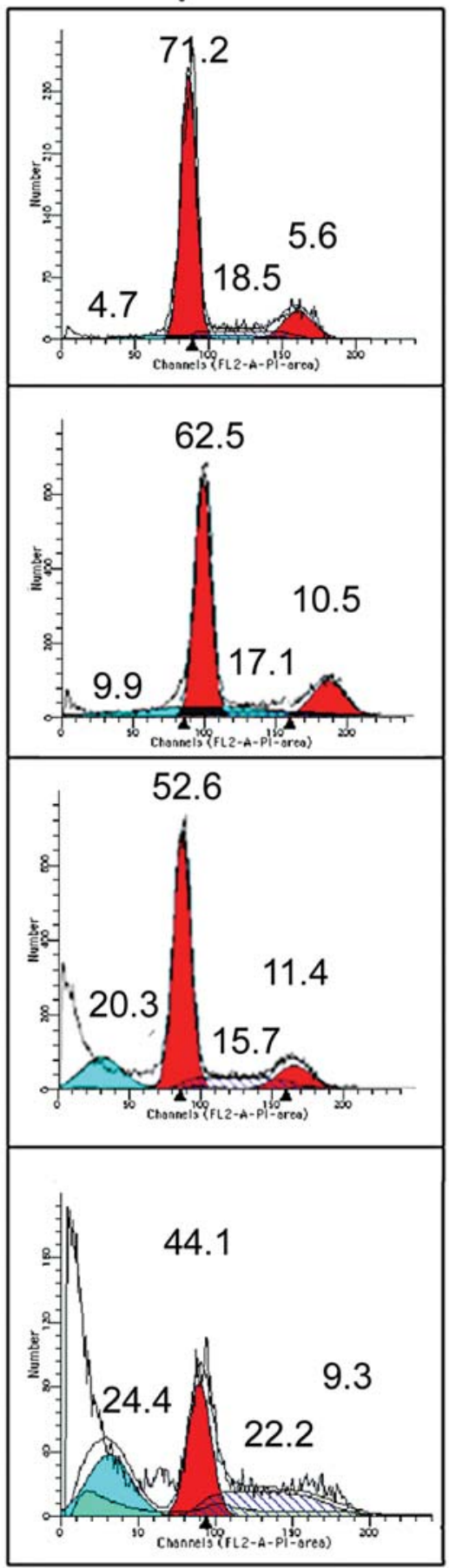


to HPRT and all changes calculated as the percent change over control.

Statistical analysis. The statistical significance between treatment groups was determined using either one-way or two-way ANOVA with Bonferroni's post-test using GraphPad Prism 2.0.

\section{Results}

Cer treatment induces a cell cycle arrest in $G_{0} / G_{1}$, followed by evidence of apoptosis. The cytotoxic effects of exogenous ceramide in breast cancer cells are well-established, as we and others have shown that treatment with exogenous ceramide induces apoptosis in both chemosensitive and chemoresistant breast cancer cells $(5,15,28,29)$. While several reports have documented the ability of ceramide to induce growth arrest in various cell models (30-34), the cytostatic effects of exogenous ceramide treatment in breast cancer are less well-defined. In order to examine the anti-proliferative effects of ceramide treatment in breast cancer, we investigated the effect of exogenous ceramide on the cell cycle progression of MCF-7 cells using flow cytometric analysis of propidium iodide stained cells. MCF-7 cells were first cultured in serum-free media for $24 \mathrm{~h}$ prior to Cer treatment in order to synchronize cells in the $G_{0} / G_{1}$-phase (Fig. 1A). Following synchronization, the medium was replaced with media containing $10 \%$ serum with either vehicle (ethanol) or $30 \mu \mathrm{M}$ Cer for 18-36 h. After $18 \mathrm{~h}$ of ceramide treatment, the percentage of cells in the $\mathrm{G}_{0} / \mathrm{G}_{1}$-phase was 2.5 -fold higher in the ceramide-treated cells (from $28.1 \%$ to $71.2 \%$ for vehicle- and ceramide-treated, respectively), with a 1.8 -fold and 6-fold decrease in the percentage of cells in the S-phase and $\mathrm{G}_{2} / \mathrm{M}$-phases (vehicle as compared to ceramide-treated) (Fig. 1B). Treatment of MCF-7 cells with DH-Cer, the commonly used negative control for Cer treatment, elicited a small increase in the population of cells in the $G_{0} / G_{1}$-phase at $18 \mathrm{~h}$, but this increase was not significant (data not shown). The cell cycle profile of ceramide-treated MCF-7 cells after $24 \mathrm{~h}$ was comparable to that seen at $18 \mathrm{~h}$ (Fig. 1B), with a higher percentage of ceramide-treated cells remaining in the $\mathrm{G}_{0} / \mathrm{G}_{1}$ phase as compared to vehicle-treated control cell $(62.5 \pm 3 \%$ as compared with $44.9 \pm 5 \%$ in ceramide- or vehicle-treated samples, respectively). After $30 \mathrm{~h}$ of ceramide treatment, the $\mathrm{G}_{0} / \mathrm{G}_{1}$ population was smaller as compared to the previous time points, as cells in $\mathrm{G}_{0} / \mathrm{G}_{1}$ population appeared to be lost to a growing percentage of cells in the apoptotic fraction. This trend was more marked at $36 \mathrm{~h}$ of ceramide treatment where the percentage of cells in the $\mathrm{G}_{0} / \mathrm{G}_{1}$-phase fell to $44.1 \%$, while the apoptotic fraction rose to $24.4 \%$ (Fig. 1B). These observations indicate that exogenous Cer treatment arrests MCF-7 breast cancer cells at $\mathrm{G}_{0} / \mathrm{G}_{1}$, which is followed by induction of apoptosis.

Cer treatment decreases the expression of cyclins $D$ and $E$. To investigate the molecular events associated with Cer-induced growth arrest, we examined the consequence of Cer treatment on the expression of cell cycle regulatory proteins. We hypothesized that Cer treatment altered the expression of cyclin

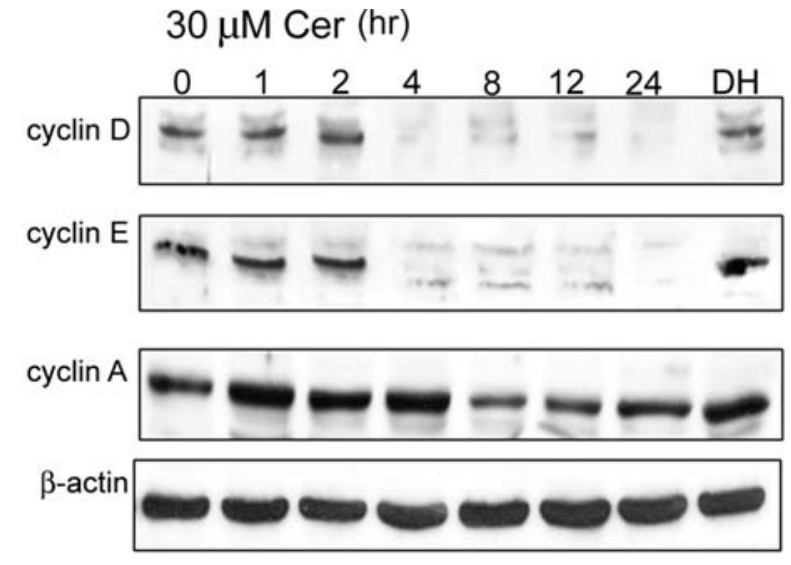

Figure 2. Exogenous ceramide decreases cyclin expression. MCF-7 cells were plated at $2 \times 10^{6}$ cells per $75 \mathrm{~cm}^{2}$ and allowed to adhere overnight. The following day the cells were treated with $30 \mu \mathrm{M}$ Cer, or $30 \mu \mathrm{M} \mathrm{DH}-C e r$ for $24 \mathrm{~h}$, for the indicated times and immunoblotting was used to probe for protein expression of cyclins D, E, or A. B-actin was used a loading control.

proteins since proper expression of the cyclins is required for progression of cells through the different phases of the cell cycle. We found that Cer treatment significantly decreased the protein expression of cyclins D and E within $4 \mathrm{~h}$ of treatment $(90 \pm 11 \%$ and $82 \pm 12 \%$ decrease for cyclins D and E respectively, $\mathrm{p}<0.01$ ), and that the expression of cyclins $\mathrm{D}$ and $\mathrm{E}$ remained suppressed for the duration of the treatment time (Fig. 2). While Cer treatment also diminished the expression of cyclin A (Fig. 2), the decrease in cyclin A expression occurred later and was only significant at the 12-h time-point $(47 \pm 14 \%$ decrease, $\mathrm{p}<0.05)$ (Fig. 2). Semiquantitative reverse transcriptase PCR (RT-PCR) analysis demonstrated that Cer treatment decreased cyclin mRNA expression similarly to the observed changes in protein expression described above (data not shown)

Cer treatment increases the expression of p53 and p21. The tumor suppressor gene p53 is one of the key mediators of cell cycle arrest following exposure to chemotherapeutic agents and radiation, and is the most commonly implicated mechanism of $\mathrm{G}_{1}$-phase arrest following drug exposure. To examine whether Cer-induced growth arrest was associated with changes in the p53 pathway, immunoblotting was used to determine the effect of Cer treatment on the expression of p53, and its downstream transcriptional target, p21 Waf1/Kip1. Cer $(30 \mu \mathrm{M})$ induced a significant increase in $\mathrm{p} 53$ protein expression within $2 \mathrm{~h}$ of treatment $(221 \pm 23 \%$ increase $)$, which peaked at $12 \mathrm{~h}$ of Cer treatment $(630 \pm 31 \%$ increase) and remained elevated during the course of Cer treatment (Fig. 3). Cer treatment also increased the expression of p21 Waf1/Kip within $1 \mathrm{~h}$ of treatment $(378 \pm 26 \%$ increase), which also peaked at $12 \mathrm{~h}$ of treatment $(702 \pm 52 \%)$, and remained elevated over the course of treatment (Fig. 3).

Semi-quantitative RT-PCR was used to determine if Cer treatment altered the expression of p53 or p21 at the mRNA level. We found that $30 \mu \mathrm{M}$ Cer increased p53 mRNA levels within $2 \mathrm{~h}$ of treatment and remained elevated over the course of treatment, however, the increase in p53 mRNA was only significant between 2 and 8 h (Fig. 4). Expression of p21 


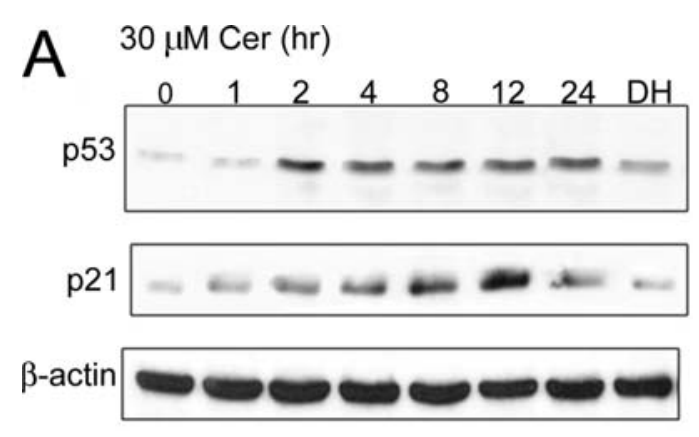

B
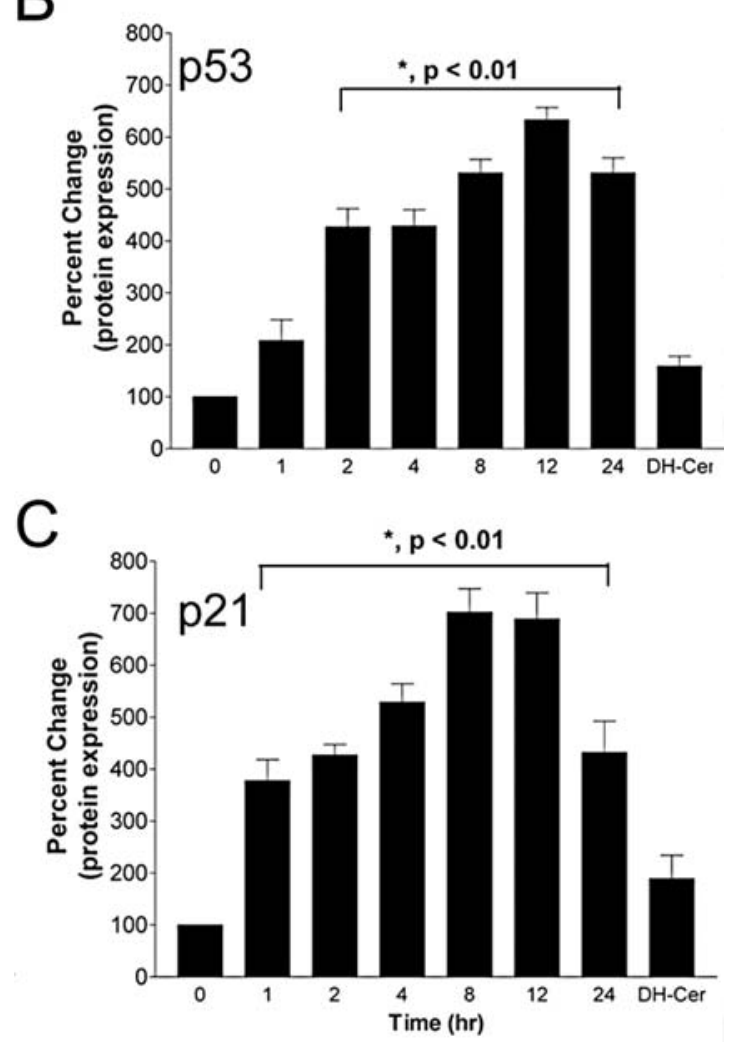

Figure 3. Ceramide treatment increases the expression of p53 and p21. MCF-7 cells were plated at $2 \times 10^{6}$ cells per $75 \mathrm{~cm}^{2}$ and allowed to adhere overnight. (A) MCF-7 cells were treated with $30 \mu \mathrm{M}$ Cer for the indicated times, or $30 \mu \mathrm{M} \mathrm{DH}-\mathrm{Cer}$ for $24 \mathrm{~h}$. The cells were then harvested and immunoblotting was used to determine the expression of p53 or p21. B-actin was used a loading control. Densitometric analysis of the relative changes in the expression of p53 (B) and p21 (C) protein expression was determined with Quantity One software as described in Materials and methods.

mRNA was significantly elevated within $1 \mathrm{~h}$ of Cer treatment and remained elevated for the remainder of the treatment time (Fig. 4). It should be noted that the observed increase in p53 was modest with the maximal induction only $50 \pm 7 \%$ higher than vehicle-treated control, while the induction in p21 mRNA expression was much greater (maximal induction $731 \pm 48 \%$ over control). However, the observed increase in protein expression during Cer treatment was comparable between p53 and p21. This suggests that the increased expression of p21 mRNA and protein is a direct result of p53 transcriptional activation, while the increase in p53 protein likely results from increased stabilization.

Inhibition of p53 sensitizes MCF-7 cells to Cer-induced cell death. Since Cer treatment induced time-dependent changes to

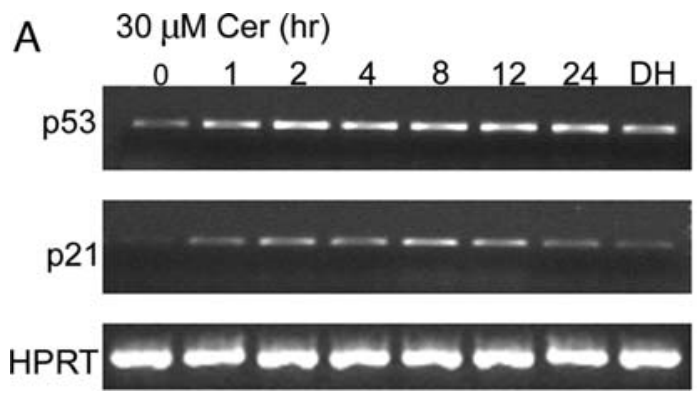

B

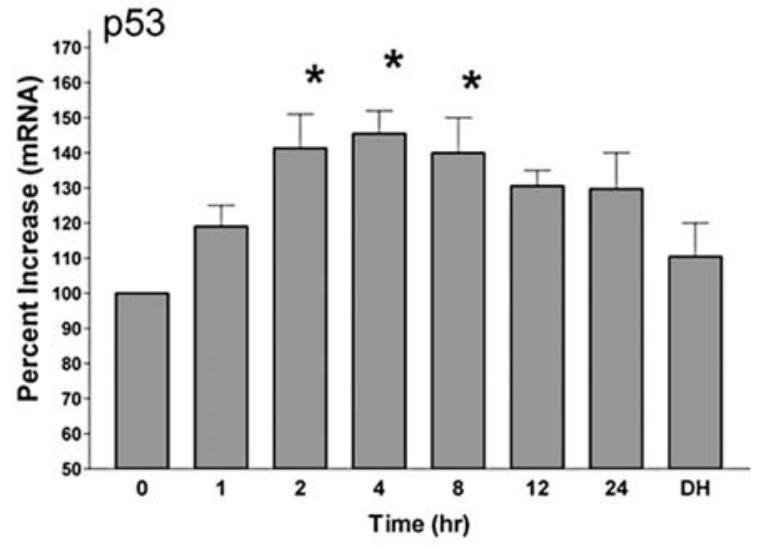

C

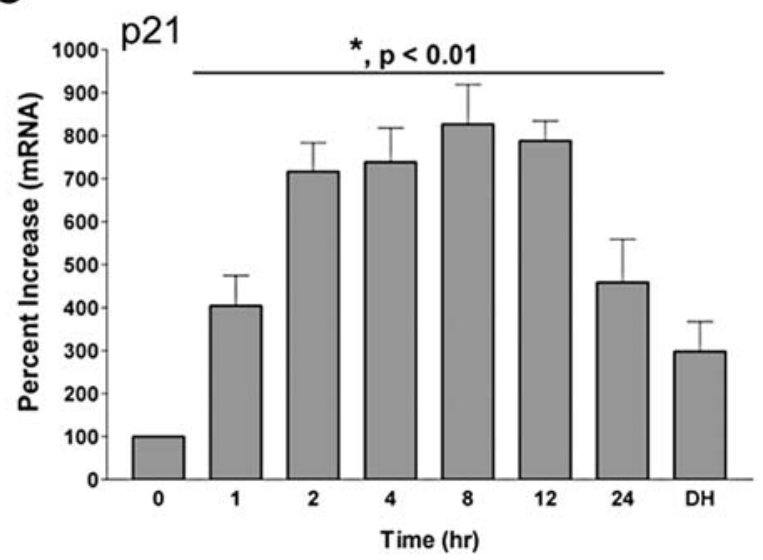

Figure 4. Ceramide treatment increases p53 and p21 mRNA expression. (A) MCF-7 cells were treated with $30 \mu \mathrm{M}$ Cer for the indicated times, or $30 \mu \mathrm{M}$ DH-Cer for $24 \mathrm{~h}$. The cells were then harvested and total cellular RNA was isolated. Cellular cDNA was generated and used in PCR to probe for p53. HPRT was used as a control. Densitometric analysis of p53 (B) and p21 (C) mRNA expression was analyzed with Quantity One software as described in Materials and methods.

the cell cycle profile of MCF-7 cells, which was accompanied by changes in the expression of p53, p21, and other cell cycle regulators, we examined the role of p53 in mediating the antiproliferative effects of Cer. We originally hypothesized that Cer-induced cell cycle arrest was dependent on up-regulation of p53 and that inhibition of p53 would protect cells from Cer-induced inhibition of proliferation and survival. We used a small-molecule inhibitor of p53-mediated transcription, pifithrin $\alpha(\mathrm{PTH} \alpha)$, to test this hypothesis $(35,36)$. We pretreated MCF-7 cells with $10 \mu \mathrm{M}$ PTH $\alpha$, a concentration that did not produce significant toxicity in MCF-7 cells, for $1 \mathrm{~h}$ prior to addition of Cer. Unexpectedly, inhibition of p53 

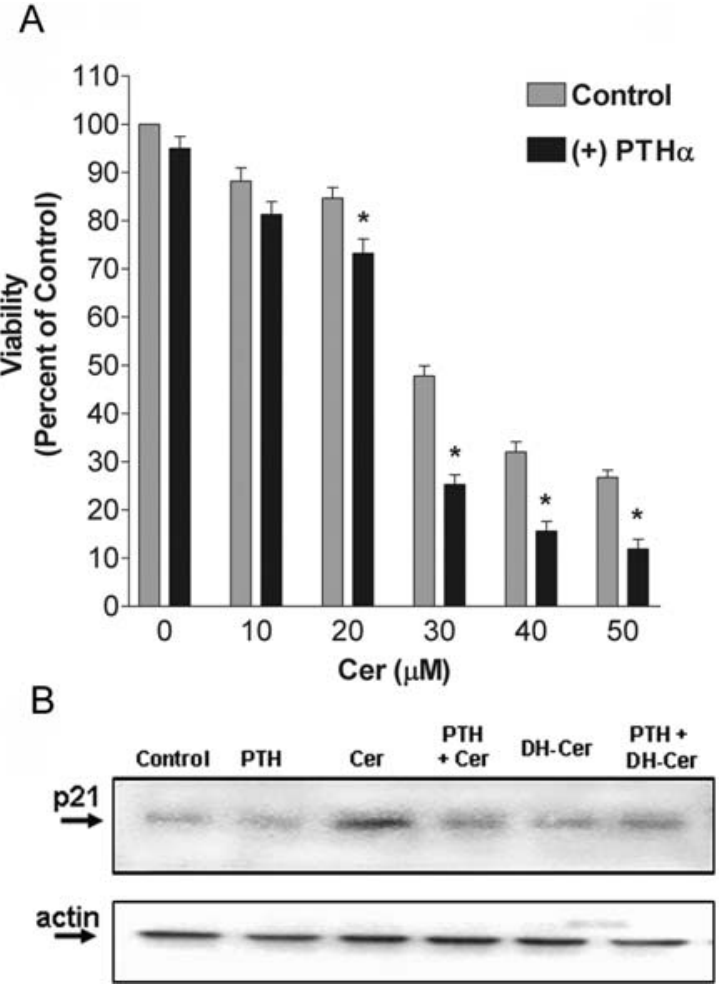

Figure 5. Inhibition of p53 transcription enhances Cer-induced changes in MCF-7 viability. (A) MCF-7 cells were either treated with the indicated concentrations of Cer for $24 \mathrm{~h}$, or pretreated with $10 \mu \mathrm{M} \mathrm{PTH} \alpha$ for $1 \mathrm{~h}$ followed by treatment with Cer for $24 \mathrm{~h}$. Following incubation, cell viability was estimated using an MTT viability assay. Data are presented as percent viability of vehicle-treated control cells $\left({ }^{*} \mathrm{p}<0.01\right.$ as compared to samples without PTH $\alpha$ ). (B) MCF-7 cells were treated with either vehicle (ethanol), $30 \mu \mathrm{M}$ Cer, or $30 \mu \mathrm{M} \mathrm{DH}-\mathrm{Cer}$; or pretreated with $10 \mu \mathrm{M}$ PTH $\alpha$ for $1 \mathrm{~h}$ followed by $30 \mu \mathrm{M}$ Cer or $30 \mu \mathrm{M}$ DH-Cer for $8 \mathrm{~h}$. The cells were then harvested and immunoblotting was used to detect the cellular expression of p21 or actin (loading control).

activity with PTH $\alpha$ enhanced the Cer-induced inhibition of MCF-7 cell viability $(76.8 \pm 3.1 \%$ decrease in viability as compared to $50.2 \pm 4.4 \%$ decrease in viability with Cer alone) (Fig. 5A). Immunoblot analysis of $\mathrm{p} 21$ expression demonstrated that PTH pretreatment inhibited p53-mediated transcription as pretreatment with PTH inhibited the Cerinduced increase in $\mathrm{p} 21$ expression demonstrated previously (Fig. 5B).

Transfection with p53 shRNA sensitizes MCF-7 cells to Cerinduced cell death. To confirm that the enhanced decrease in MCF-7 cell viability during p53 inhibition with PTH pretreatment was not a non-selective effect of PTH on other signaling pathways, an expression plasmid for a short-hairpin siRNA sequence directed against p53 (shRNA p53) was also used to selectively inhibit p53 transcription. Similar to the results found using the pharmacological inhibitor, transfection of MCF-7 cells with shRNA p53 prior to Cer treatment enhanced Cer-mediated inhibition of cell viability over transfection with the pSUPER control plasmid $(77.0 \pm 6$ as compared to $51.3 \pm 5$ for shRNA p $53+$ Cer and pSUPER+Cer, respectively) (Fig. 6A). Immunoblotting verified that the shRNA p53 construct inhibited the protein expression of p53. Transfection of MCF-7 cells with the control pSUPER vector led to a slight, but insignificant, increase in p53 expression and

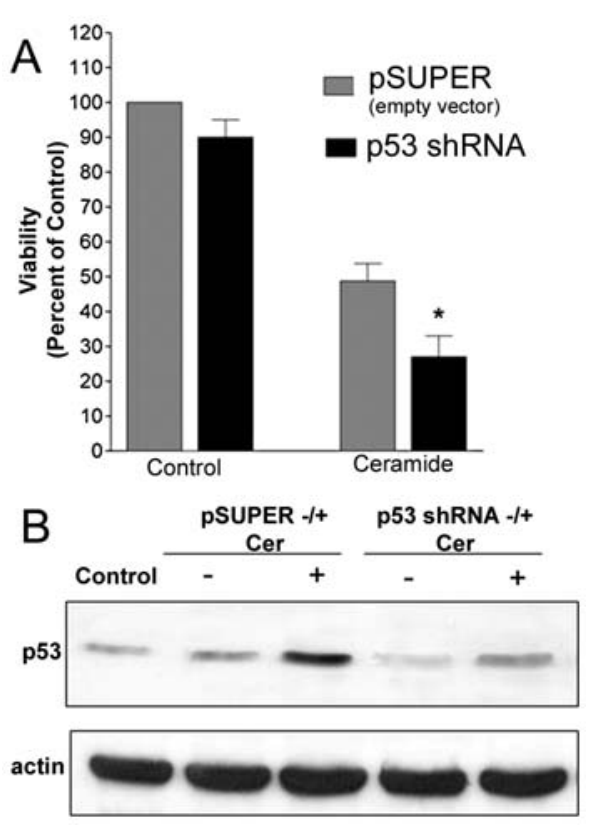

Figure 6. Transfection with p53 shRNA plasmid enhances Cer-induced inhibition of MCF-7 viability. (A) MCF-7 cells were plated at $2.5 \times 10^{5}$ cells per 96-well plate in phenol-free DMEM. The following day, the cells were transfected with $50 \mathrm{ng} /$ well pSUPER or pSUPER p53 shRNA for $30 \mathrm{~h}$. The cells were then treated with the indicated concentrations of Cer for $24 \mathrm{~h}$. Data are presented as percent viability as compared to vehicle-treated control cells. Mean values \pm SE of three different experiments in quadruplicate are reported $\left({ }^{*} \mathrm{p}<0.01\right.$ as determined by two-way ANOVA). (B) MCF-7 cells were transfected with either pSUPER or pSUPER shRNA p53 for $30 \mathrm{~h}$, followed by treatment with $30 \mu \mathrm{M}$ Cer for $8 \mathrm{~h}$. The cells were then harvested and immunoblotting was used to determine the expression of p53 or actin (loading control). The picture shown is a representative of three separate experiments.

did not affect the Cer-induced rise in $\mathrm{p} 53$, while transfection with p53 shRNA inhibited both basal and Cer-induced p53 expression (Fig. 6B).

Inhibition of p53 switches the cellular response to Cer treatment from growth arrest to apoptosis. In order to explore the mechanism behind the sensitization of MCF-7 cells to ceramide treatment during inhibition of p53 activity, flow cytometry was used to determine the consequence of PTH-mediated inhibition of p53 transcription on the cell cycle profile of Cer-treated cells. Interestingly, pretreatment with $10 \mu \mathrm{M}$ PTH prior to the addition of exogenous Cer reduced the percentage of cells arrested in $\mathrm{G}_{0} / \mathrm{G}_{1}$-phase from $71.2 \pm 5.1 \%$ to $53.0 \pm 3.3 \%$ (Fig. 7). The PTH-induced decrease in the $\mathrm{G}_{0} / \mathrm{G}_{1}$-phase population during Cer treatment was accompanied by a significant increase the percentage of cells found in the sub- $G_{1}$ or apoptotic fraction (from $4.7 \pm 2.6 \%$ to $19.5 \pm 3.5 \%$, $\mathrm{p}<0.05)$. These data suggest that inhibition of $\mathrm{p} 53$-mediated transcription alters the response of MCF-7 cells to Cer treatment from growth arrest to apoptosis.

p21 siRNA also leads to enhanced MCF-7 cell death during Cer treatment. To determine which downstream target of $\mathrm{p} 53$ might be involved in the enhancement of ceramide-induced death following inhibition of p53, we investigated the effect of inhibition of p21 expression, a well-defined effector of p53-mediated growth arrest following exposure to a number 


\section{Ceramide}

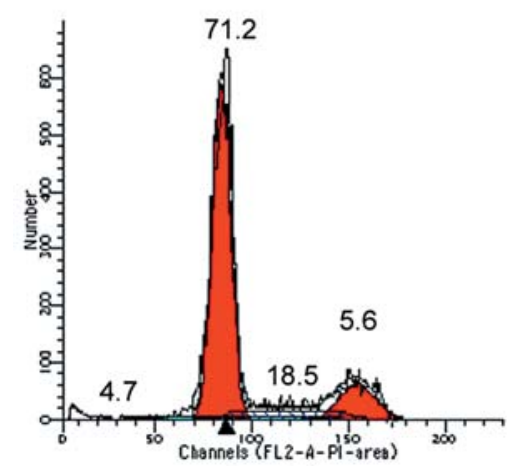

PTH + Ceramide

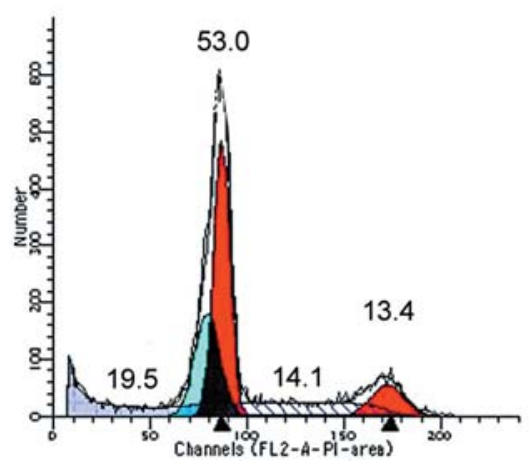

Figure 7. Pharmacologic inhibition of p53 increases the percentage of apoptotic MCF-7 cells. MCF-7 cells were plated at $1.5 \times 10^{6}$ cells per 75 cm ${ }^{2}$ dish and allowed to adhere overnight. The following day, culture was replaced with serum-free media for $24 \mathrm{~h}$. The medium was then replaced with $10 \%$ DMEM, and cells were either treated with Cer $(30 \mu \mathrm{M})$, or pretreated with $10 \mu \mathrm{M} \mathrm{PTH}$ for $1 \mathrm{~h}$ followed by $30 \mu \mathrm{M}$ Cer, for $18 \mathrm{~h}$. The cells were harvested, fixed in $70 \%$ ethanol, stained with PI, and analyzed with FACS to determine DNA content. Percentage of cells in each population of the cell cycle was determined using ModFit Pro Analysis software. The percentage of cells in the apoptotic, sub- $\mathrm{G}_{1}$ (blue shaded region), $\mathrm{G}_{0} / \mathrm{G}_{1}$ (leftmost red region), $\mathrm{S}$ (hatched shaded region) or $\mathrm{G}_{2} / \mathrm{M}$ (rightmost shaded region) phase of the cell cycle was determined using ModFit Pro Analysis software, and are the average percentages from three separate experiments.

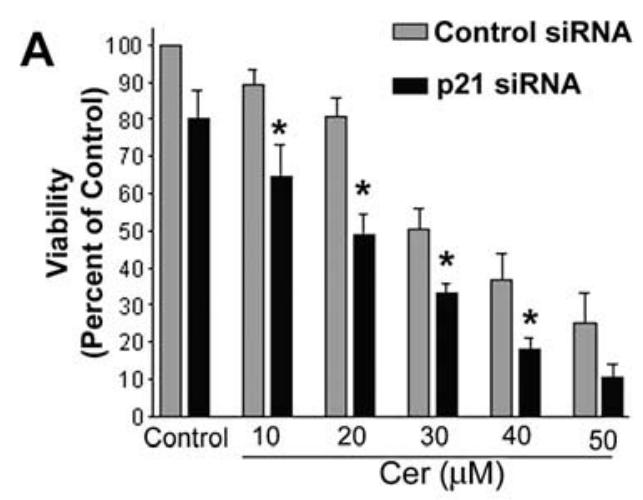

B

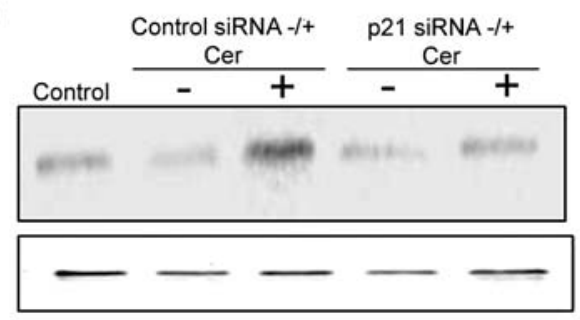

Figure 8. Transfection of MCF-7 cells with p21 siRNA enhances Cer-induced cytotoxicity. (A) MCF-7 cells were transfected with non-targeting, scrambled siRNA (control) or p21 siRNA for $30 \mathrm{~h}$. The cells were then treated with the indicated concentrations of Cer for $24 \mathrm{~h}$. Data are presented as percent viability of vehicle-treated control cells. Mean values \pm SE of three different experiments in quadruplicate are reported $\left({ }^{*} \mathrm{p}<0.01\right.$ as compared to control siRNA-transfected cells). (B) MCF-7 cells were transfected with nontargeting, scrambled siRNA (control) or p21 siRNA for $30 \mathrm{~h}$, followed by treatment with $30 \mu \mathrm{M}$ Cer for $8 \mathrm{~h}$. The cells were then harvested and immunoblotting was used to determine the expression of $\mathrm{p} 21$ or actin (loading control). The picture shown is a representative of three separate experiments.

to agents, on Cer-induced cytotoxicity. While p21 is an established mediator of both p53-dependent growth arrest and apoptosis $(37,38)$, however in some cases, p21 has been demonstrated to protect cells from apoptosis through its ability to induce growth arrest (39-42). siRNA targeted to p21 was used to knock-down p21 expression prior to exogenous
Cer treatment. Similar to the results with agents that inhibited p53 transcription (Fig. 8A), inhibition of p21 expression led to a significant increase in cell death following Cer treatment ( $71.7 \pm 3.7 \%$ as compared to $44.4 \pm 6.2 \%$ for $\mathrm{p} 21$ siRNA and control, non-targeted siRNA, respectively). Immunoblotting again demonstrated that transfection with $\mathrm{p} 21$ siRNA decreases the basal and Cer-induced expression of p21 (Fig. 8B). These data suggest that the enhanced cell death during Cer treatment following inhibition of p53 transcription may be due to a diminution of $\mathrm{p} 21$ protein expression.

\section{Discussion}

Significant progress has been made over the past decade towards understanding the contribution of intracellular ceramide signaling in tumor sensitivity to chemotherapeutic agents, with induction of ceramide and ceramide signaling essential to the effectiveness of many chemotherapeutic agents. Defects in ceramide generation and metabolism have also been implicated as a common mechanism of resistance to many chemotherapeutic agents. Therefore, understanding the downstream signaling mechanisms involved in ceramide's anti-proliferative effects in tumors will help in designing more effective chemotherapeutic treatment regimens that effectively target ceramide signaling. Here we demonstrate that treatment with exogenous ceramide prevents the progression of MCF-7 cells from the $\mathrm{G}_{0} / \mathrm{G}_{1}$-phase of the cell cycle. Prolonged arrest of MCF-7 cells in the $G_{0} / G_{1}$-phase was followed by evidence of apoptosis, as manifested by an increase in the population of cells that were undergoing DNA degradation (population of cells with sub-G $\mathrm{G}_{1} \mathrm{DNA}$ ). Cell cycle arrest was associated with increased p53 and p21 mRNA and protein, as well as the diminished expression of cyclins D and E. Inhibition of p53-mediated transcription sensitized MCF-7 cells to Cer treatment, most likely as a result of decreased transcriptional activation of $\mathrm{p} 21$.

The cytotoxic and cytostatic effects of ceramide have been reported to be both dependent and independent of 
p53 signaling. Several studies have demonstrated that p53 activation regulates ceramide generation (43-46). In these studies, cytotoxic stress, such as $\gamma$ radiation, actinomycin D, or etoposide, increased ceramide generation through p53dependent increases in reactive oxygen species (ROS) and neutral sphingomyelinase activation (43-45). Cells with either mutant p53 or that expressed the E6 protein of the human papillomavirus demonstrated diminished ceramide production and increased resistance to cell death, suggesting that ceramide generation lay downstream of p53 induction. However, in these same cell models, p53-independent regulation of ceramide generation in response to other, different cytotoxic agents was also observed $(43,46)$ suggesting that the dependence on p53 for ceramide generation may be stimulus-specific. In contrast to the reports listed above, several groups have demonstrated a clear increase in $\mathrm{p} 53$ protein expression following addition of exogenous ceramide (47-51). In these studies, short-chain, cell-permeable ceramides were used to increase intracellular ceramide concentrations rather than a chemotherapeutic or cytotoxic agent, and it is tempting to speculate that this is the explanation for the differences in the findings of the studies. However, while the majority of studies demonstrate that exogenous ceramide leads to induction of p53 expression, it seems that in some cell types exogenous ceramide treatment does not result in increased p53 expression $(38,46,52)$. Thus the relationship between ceramide signaling and p53 induction may be both cell-type and stimulus specific.

In this study we find that exogenous Cer treatment increases both p53 and p21 expression at the mRNA and protein level. The induction of p53 protein was much greater than the induction of p53 mRNA (630\% versus 50\%). Expression of p53 is reported to be primarily regulated by changes in protein degradation. Under normal cellular conditions p53 is a shortlived protein with $\mathrm{at}_{1 / 2}$ of $\sim 30 \mathrm{~min}$, which is ubiquitinated and eliminated through proteosomal degradation (16). Upon exposure to stress stimuli, including DNA damaging agents, hypoxia, and microtubule-interacting agents, ubiquitination of p53 protein is prevented and p53 accumulates. While stabilization of p53 is thought to be the main mechanism for p53 induction, in some situations, p53 expression has been shown to be regulated at the mRNA level by various transcription factors (53). In the case of Cer treatment, the greater induction of $\mathrm{p} 53$ protein suggests that stabilization of p53 protein constitutes the most prominent mechanism of p53 induction in response to Cer treatment. This is in contrast with the induction of $\mathrm{p} 21$, which was found to be dramatically induced at both the mRNA and protein level. p21 is a target of p53 transcriptional activation; therefore it is expected that induction of $\mathrm{p} 21$ would occur both at the mRNA and protein level. p21 mRNA and protein levels were significantly increased within $1 \mathrm{~h}$, while p53 expression did not rise significantly until $2 \mathrm{~h}$, which may reflect p53-independent mechanisms of p21 induction by Cer. In addition to p53, the p21 promoter contains binding sites for NF- $\mathrm{KB}(54,55)$, STAT $(56,57)$, Sp-1 (58), and AP-1 transcription factors (59), all of which may influence the expression of $\mathrm{p} 21$ in response to Cer treatment.

Treatment with exogenous Cer led to a dramatic decrease in the expression of cyclins D and E. Cyclin D is primarily associated with progression through $\mathrm{G}_{1}$-phase, while adequate expression of the cyclin $\mathrm{E}$ protein is required for the transition from $G_{1}$ into the $S$-phase. The decrease in cyclins $D$ and $E$ expression correlates with the data in Fig. 2 demonstrating a selective arrest of cells in $\mathrm{G}_{0} / \mathrm{G}_{1}$ following Cer exposure. The decreased expression of $\mathrm{D}$ and $\mathrm{E}$ would prevent formation of a sufficient cyclin D/CDK2, and cyclin E/CDK4 or cyclin E/ CDK2 complexes, which are necessary for CDK activation and progression through the cell cycle from $\mathrm{G}_{1}$ and into $\mathrm{S}$-phase. Other reports have indicated that ceramide leads to the downregulation of cyclin A expression $(34,60,61)$. While we also observed that ceramide treatment led to a decreased expression of cyclin A, the decrease in cyclin A expression is much less than that observed for cyclins $\mathrm{D}$ and $\mathrm{E}$ which correlates with arrest in Cer-treated cells in $\mathrm{G}_{0} / \mathrm{G}_{1}$.

The ability of Cer to induce p53 is interesting since p53 is most commonly studied for mediation of growth arrest and apoptosis in response to agents that cause DNA damage or genotoxic stress (62), although p53 has been shown to be induced by other agents that do not directly involve DNA damage (36). While there is no evidence in the literature that demonstrates a direct interaction of ceramide with DNA, ceramide can lead to the generation of reactive oxygen species and oxidative stress $(63,64)$, which can lead to damage to cellular components including DNA and RNA. Therefore, it is possible that DNA damage may occur downstream of ceramide-induced ROS generation, which leads to induction of p53 (65-67). The response of cells to the proposed ceramideinduced damage may be cell-type specific since induction of p53 is not consistently demonstrated during ceramide treatment $(33,34,37,38,50,61,68,69)$.

Since Cer-induced growth arrest was associated with an increased expression of p53, which influences growth arrest and apoptosis, our initial hypothesis was that inhibition of MCF-7 cell viability by Cer was mediated, at least in part, by p53 and that inhibition of p53 would protect from Cer-induced changes in cell number. Interestingly, the observed changes in MCF-7 cell viability following pharmacologic or genetic inhibition of p53 did not support this hypothesis. Treatment with PTH $\alpha$ and p53 siRNA led to significant enhancements of MCF-7 cell cytotoxicity over Cer-treatment alone. In addition, pre-treatment with PTH $\alpha$ led the appearance of an apoptotic (sub- $\mathrm{G}_{1}$ ) population during an $18 \mathrm{~h}$ Cer treatment (where formerly only growth arrest was observed), suggesting that inhibition of p53-mediated transcription during Cer treatment switches the cellular response from growth arrest to apoptosis. This switch may be the result of inhibition of p53-dependent induction of p21 since we observed that inhibition of p21 expression with siRNA also resulted in a sensitization to Cerinduced cytotoxicity over Cer treatment alone. p53-mediated induction of p21 expression may act to protect MCF-7 cells from Cer-induced apoptosis by selectively inducing growth arrest in the $\mathrm{G}_{1}$-phase, at least acutely. While p21 has been implicated in mediating p53-dependent apoptosis in response to some chemotherapeutic agents, our findings supported by a body of literature demonstrate that p21 can act as antiapoptotic factor in MCF-7 cells $(70,71)$, as well as other tumor cell lines $(20,40,72)$. This information may be clinically relevant since induction of apoptosis is the preferred treatment response over growth arrest. Finally, the ability of Cer to induce apoptosis over growth arrest in the presence of 
p53 inactivation would make Cer-based therapies particularly useful in the treatment of breast cancer, as mutations in the p53 gene are reported to occur in $30-50 \%$ of all breast tumors $(73,74)$.

\section{Acknowledgements}

We are grateful to Dr Aline Scandurro for her expert help with the flow cytometry and analysis of the cell cycle data. We would also like to acknowledge Dr Gilbert Morris for his helpful discussions and providing the dominant negative p53 construct. The excellent technical assistance from Dr Yan Tang is deeply appreciated. This work was partially supported by a Department of Defense Breast Cancer Research Grant DAMD17-01-1-0432 (A.P.S).

\section{References}

1. Kolesnick RN and Clegg S: 1,2-Diacylglycerols, but not phorbol esters, activate a potential inhibitory pathway for protein kinase $\mathrm{C}$ in $\mathrm{GH} 3$ pituitary cells. Evidence for involvement of a sphingomyelinase. J Biol Chem 263: 6534-6537, 1988.

2. Chatterjee S: Neutral sphingomyelinase action stimulates signal transduction of tumor necrosis factor-alpha in the synthesis of cholesteryl esters in human fibroblasts. J Biol Chem 269: 879-882, 1994.

3. Okamoto Y, Obeid LM and Hannun YA: Bcl-xL interrupts oxidative activation of neutral sphingomyelinase. FEBS Lett 530: 104-108, 2002

4. Schutze S, Potthoff K, Machleidt T, et al: TNF activates NFkappa B by phosphatidylcholine-specific phospholipase Cinduced 'acidic' sphingomyelin breakdown. Cell 71: 765-776, 1992

5. Senchenkov A, Litvak DA and Cabot MC: Targeting ceramide metabolism - a strategy for overcoming drug resistance. J Natl Cancer Inst 93: 347-357, 2001

6. Litvak DA, Bilchik AJ and Cabot MC: Modulators of ceramide metabolism sensitize colorectal cancer cells to chemotherapy: novel treatment strategy. J Gastrointest Surg 7: 140-148, 2003.

7. Olshefski RS and Ladisch S: Glucosylceramide synthase inhibition enhances vincristine-induced cytotoxicity. Int J Cancer 93: 131-138, 2001

8. Di Bartolomeo S and Spinedi A: Differential chemosensitizing effect of two glucosylceramide synthase inhibitors in hepatoma cells. Biochem Biophys Res Commun 288: 269-274, 2001

9. Michael JM, Lavin MF and Watters DJ: Resistance to radiationinduced apoptosis in Burkitt's lymphoma cells is associated with defective ceramide signaling. Cancer Res 57: 3600-3605, 1997.

10. Chmura SJ, Nodzenski E, Beckett MA, et al: Loss of ceramide production confers resistance to radiation-induced apoptosis. Cancer Res 57: 1270-1275, 1997.

11. Ogretmen B and Hannun YA: Updates on functions of ceramide in chemotherapy-induced cell death and in multidrug resistance. Drug Resist Updat 4: 368-377, 2001.

12. Cai Z, Bettaieb A, Mahdani NE, et al: Alteration of the sphingomyelin/ceramide pathway is associated with resistance of human breast carcinoma MCF7 cells to tumor necrosis factor-alphamediated cytotoxicity. J Biol Chem 272: 6918-6926, 1997.

13. Wang XZ, Beebe JR, Pwiti L, et al: Aberrant sphingolipid signaling is involved in the resistance of prostate cancer cell lines to chemotherapy. Cancer Res 59: 5842-5848, 1999.

14. Itoh M, Kitano T, Watanabe M, et al: Possible role of ceramide as an indicator of chemoresistance: decrease of the ceramide content via activation of glucosylceramide synthase and sphingomyelin synthase in chemoresistant leukemia. Clin Cancer Res 9: 415-423, 2003

15. Struckhoff AP, Bittman R, Burow ME, et al: Novel ceramide analogs as potential chemotherapeutic agents in breast cancer. J Pharmacol Exp Ther 309: 523-532, 2004.

16. Blagosklonny MV: Loss of function and $\mathrm{p} 53$ protein stabilization. Oncogene 15: 1889-1893, 1997.

17. Poluha W, Poluha DK, Chang B, et al: The cyclin-dependent kinase inhibitor p21 (WAF1) is required for survival of differentiating neuroblastoma cells. Mol Cell Biol 16: 1335-1341, 1996.
18. Harper JW, Adami GR, Wei N, et al: The p21 Cdk-interacting protein Cip1 is a potent inhibitor of G1 cyclin-dependent kinases. Cell 75: 805-816, 1993.

19. Formenti SC, Dunnington G, Uzieli B, et al: Original p53 status predicts for pathological response in locally advanced breast cancer patients treated preoperatively with continuous infusion 5-fluorouracil and radiation therapy. Int J Radiat Oncol Biol Phys 39: 1059-1068, 1997.

20. Aas T, Borresen AL, Geisler S, et al: Specific P53 mutations are associated with de novo resistance to doxorubicin in breast cancer patients. Nat Med 2: 811-814, 1996.

21. Brown JM and Wouters BG: Apoptosis, p53, and tumor cell sensitivity to anticancer agents. Cancer Res 59: 1391-1399, 1999.

22. Ghosh S, Mendoza T, Ortiz LA, et al: Bleomycin sensitivity of mice expressing dominant-negative p53 in the lung epithelium. Am J Respir Crit Care Med 166: 890-897, 2002.

23. Wahl AF, Donaldson KL, Fairchild C, et al: Loss of normal p53 function confers sensitization to Taxol by increasing G2/M arrest and apoptosis. Nat Med 2: 72-79, 1996.

24. Fan S, Smith ML, Rivet DJ II, et al: Disruption of p53 function sensitizes breast cancer MCF-7 cells to cisplatin and pentoxifylline. Cancer Res 55: 1649-1654, 1995.

25. Cassinelli G, Supino R, Perego P, et al: A role for loss of p53 function in sensitivity of ovarian carcinoma cells to taxanes. Int J Cancer 92: 738-747, 2001

26. Taniguchi TEH, Chikstsu N, Uchimaru K and Matsuda T: Sodium butyrate induces growth arrest and senscence-like phenotypes in gynecological cancer cells. Blood 94: 257-267, 2001.

27. Scandurro AB and Beckman BS: Common proteins bind mRNAs encoding erythropoietin, tyrosine hydroxylase, and vascular endothelial growth factor. Biochem Biophys Res Commun 246: 436-440, 1998.

28. Liu YY, Han TY, Giuliano AE, et al: Expression of glucosylceramide synthase, converting ceramide to glucosylceramide, confers adriamycin resistance in human breast cancer cells. J Biol Chem 274: 1140-1146, 1999.

29. Crawford KW, Bittman R, Chun J, et al: Novel ceramide analogues display selective cytotoxicity in drug-resistant breast tumor cell lines compared to normal breast epithelial cells. Cell Mol Biol 49: 1017-1023, 2003.

30. Alesse E, Zazzeroni F, Angelucci A, et al: The growth arrest and downregulation of c-myc transcription induced by ceramide are related events dependent on p21 induction, $\mathrm{Rb}$ underphosphorylation and E2F sequestering. Cell Death Differ 5: 381-389, 1998.

31. Bourbon NA, Sandirasegarane L and Kester M: Ceramideinduced inhibition of Akt is mediated through protein kinase Czeta: implications for growth arrest. J Biol Chem 277: 3286-3292, 2002.

32. Jayadev S, Liu B, Bielawska AE, et al: Role for ceramide in cell cycle arrest. J Biol Chem 270: 2047-2052, 1995.

33. Kuroki J, Hirokawa M, Kitabayashi A, et al: Cell-permeable ceramide inhibits the growth of B lymphoma Raji cells lacking TNF-alpha-receptors by inducing G0/G1 arrest but not apoptosis: a new model for dissecting cell-cycle arrest and apoptosis. Leukemia 10: 1950-1958, 1996.

34. Lee JY, Bielawska AE and Obeid LM: Regulation of cyclindependent kinase 2 activity by ceramide. Exp Cell Res 261: 303-311, 2000 .

35. Komarov PG, Komarova EA, Kondratov RV, et al: A chemical inhibitor of p53 that protects mice from the side effects of cancer therapy. Science 285: 1733-1737, 1999

36. Culmsee C, Zhu X, Yu QS, et al: A synthetic inhibitor of p53 protects neurons against death induced by ischemic and excitotoxic insults, and amyloid beta-peptide. J Neurochem 77: 220-228, 2001.

37. Kang KH, Kim WH and Choi KH: p21 promotes ceramideinduced apoptosis and antagonizes the antideath effect of Bcl-2 in human hepatocarcinoma cells. Exp Cell Res 253: 403-412, 1999.

38. Oh WJ, Kim WH, Kang KH, et al: Induction of p21 during ceramide-mediated apoptosis in human hepatocarcinoma cells. Cancer Lett 129: 215-222, 1998

39. Chen QM, Liu J and Merrett JB: Apoptosis or senescence-like growth arrest: influence of cell-cycle position, p53, p21 and bax in $\mathrm{H}_{2} \mathrm{O}_{2}$ response of normal human fibroblasts. Biochem J 347: $543-551,2000$

40. Gorospe M, Cirielli C, Wang X, et al: p21(Waf1/Cip1) protects against p53-mediated apoptosis of human melanoma cells. Oncogene 14: 929-935, 1997. 
41. Weiss RH: $\mathrm{p} 21^{\mathrm{Waf} 1 / \mathrm{Cip} 1}$ as a therapeutic target in breast and other cancers. Cancer Cell 4: 425-429, 2003.

42. Gorospe M, Wang X, Guyton KZ, et al: Protective role of p21(Waf1/Cip1) against prostaglandin A2-mediated apoptosis of human colorectal carcinoma cells. Mol Cell Biol 16: 6654-6660, 1996.

43. Hara S, Nakashima S, Kiyono T, et al: p53-independent ceramide formation in human glioma cells during gamma-radiationinduced apoptosis. Cell Death Differ 11: 853-861, 2004.

44. Sawada M, Kiyono T, Nakashima S, et al: Molecular mechanisms of TNF-alpha-induced ceramide formation in human glioma cells: P53-mediated oxidant stress-dependent and -independent pathways. Cell Death Differ 11: 997-1008, 2004.

45. Sawada M, Nakashima S, Kiyono T, et al: p53 regulates ceramide formation by neutral sphingomyelinase through reactive oxygen species in human glioma cells. Oncogene 20: 1368-1378, 2001.

46. Dbaibo GS, Pushkareva MY, Rachid RA, et al: p53-dependent ceramide response to genotoxic stress. J Clin Invest 102: 329-339, 1998.

47. Bras A, Albar JP, Leonardo E, et al: Ceramide-induced cell death is independent of the Fas/Fas ligand pathway and is prevented by Nur77 overexpression in A20 B cells. Cell Death Differ 7: 262-271, 2000.

48. Lopez-Marure R, Ventura JL, Sanchez L, et al: Ceramide mimics tumour necrosis factor-alpha in the induction of cell cycle arrest in endothelial cells. Induction of the tumour suppressor p53 with decrease in retinoblastoma/protein levels. Eur J Biochem 267: 4325-4333, 2000.

49. Willaime S, Vanhoutte P, Caboche J, et al: Ceramide-induced apoptosis in cortical neurons is mediated by an increase in p38 phosphorylation and not by the decrease in ERK phosphorylation. Eur J Neurosci 13: 2037-2046, 2001

50. Kim SS, Chae HS, Bach JH, et al: P53 mediates ceramideinduced apoptosis in SKN-SH cells. Oncogene 21: 2020-2028, 2002.

51. Yang J and Duerksen-Hughes PJ: Activation of a p53-independent, sphingolipid-mediated cytolytic pathway in p53-negative mouse fibroblast cells treated with N-methyl-N-nitro-N-nitrosoguanidine. J Biol Chem 276: 27129-27135, 2001.

52. Kim WH, Kang KH, Kim MY, et al: Induction of p53-independent p21 during ceramide-induced G1 arrest in human hepatocarcinoma cells. Biochem Cell Biol 78: 127-135, 2000.

53. Kirch HC, Flaswinkel S, Rumpf H, et al: Expression of human p53 requires synergistic activation of transcription from the p53 promoter by AP-1, NF-kappaB and Myc/Max. Oncogene 18: 2728-2738, 1999.

54. Basile JR, Eichten A, Zacny V, et al: NF-(kappa)B-mediated induction of $\mathrm{p} 21^{\text {Cip1/Waf1 }}$ by tumor necrosis factor (alpha) induces growth arrest and cytoprotection in normal human keratinocytes. Mol Cancer Res 1: 262-270, 2003.

55. Hellin A-C, Bentires-Alj M, Verlaet M, et al: Roles of nuclear factor-kappa B, p53, and p21/WAF1 in Daunomycin-induced cell cycle arrest and apoptosis. J Pharmacol Exp Ther 295: $870-878,2000$

56. Gooch JL, Herrera RE and Yee D: The role of p21 in interferon gamma-mediated growth inhibition of human breast cancer cells. Cell Growth Differ 11: 335-342, 2000.

57. Chin YE, Kitagawa M, Su WC, et al: Cell growth arrest and induction of cyclin-dependent kinase inhibitor $\mathrm{p} 21^{\mathrm{WAF} 1 / \mathrm{CIP} 1}$ mediated by STAT1. Science 272: 719-722, 1996.

58. De Siervi A, Marinissen M, Diggs J, et al: Transcriptional activation of p21(waf1/cip1) by alkylphospholipids: role of the mitogen-activated protein kinase pathway in the transactivation of the human p21(waf1/cip1) promoter by Sp1. Cancer Res 64: 743-750, 2004.
59. Chung YW, Jeong DW, Won JY, et al: $\mathrm{H}(2) \mathrm{O}(2)$-induced AP-1 activation and its effect on $\mathrm{p} 21$ (WAF1/CIP1)-mediated G2/M arrest in a p53-deficient human lung cancer cell. Biochem Biophys Res Commun 293: 1248-1253, 2002.

60. Siddiqui RA, Jenski LJ, Harvey KA, et al: Cell-cycle arrest in Jurkat leukaemic cells: a possible role for docosahexaenoic acid. Biochem J 371: 621-629, 2003.

61. Spyridopoulos I, Mayer P, Shook KS, et al: Loss of cyclin A and G1-cell cycle arrest are a prerequisite of ceramide-induced toxicity in human arterial endothelial cells. Cardiovasc Res 50: 97-107, 2001

62. Gewirtz DA: Growth arrest and cell death in the breast tumor cell in response to ionizing radiation and chemotherapeutic agents which induce DNA damage. Breast Cancer Res Treat 62: 223-235, 2000.

63. Garcia-Ruiz C, Colell A, Mari M, et al: Direct effect of ceramide on the mitochondrial electron transport chain leads to generation of reactive oxygen species. Role of mitochondrial glutathione. J Biol Chem 272: 11369-11377, 1997.

64. Gudz TI, Tserng K-Y and Hoppel CL: Direct inhibition of mitochondrial respiratory chain complex III by cell-permeable ceramide. J Biol Chem 272: 24154-24158, 1997.

65. Suematsu N, Tsutsui H, Wen J, et al: Oxidative stress mediates tumor necrosis factor-alpha-induced mitochondrial DNA damage and dysfunction in cardiac myocytes. Circulation 107: 1418-1423, 2003.

66. Guidarelli A, Clementi E, De Nadai C, et al: TNFalpha enhances the DNA single-strand breakage induced by the short-chain lipid hydroperoxide analogue tert-butylhydroperoxide via ceramidedependent inhibition of complex III followed by enforced superoxide and hydrogen peroxide formation. Exp Cell Res 270: 56-65, 2001.

67. Galvano F, Campisi A, Russo A, et al: DNA damage in astrocytes exposed to fumonisin B1. Neurochem Res 27: 345-351, 2002.

68. Maurer BJ, Melton L, Billups C, et al: Synergistic cytotoxicity in solid tumor cell lines between $\mathrm{N}$-(4-hydroxyphenyl)retinamide and modulators of ceramide metabolism. J Natl Cancer Inst 92: 1897-1909, 2000

69. Santana P, Pena LA, Haimovitz-Friedman A, et al: Acid sphingomyelinase-deficient human lymphoblasts and mice are defective in radiation-induced apoptosis. Cell 86: 189-199, 1996.

70. Jiang Y and Porter AG: Prevention of tumor necrosis factor (TNF)-mediated induction of $\mathrm{p} 21^{\mathrm{WAF} 1 / \mathrm{CIP} 1}$ sensitizes MCF-7 carcinoma cells to TNF-induced apoptosis. Biochem Biophys Res Commun 245: 691-697, 1998.

71. Drane P, Leblanc V, Miro-Mur F, et al: Accumulation of an inactive form of $\mathrm{p} 53$ protein in cells treated with TNF alpha. Cell Death Differ 9: 527-537, 2002.

72. Vancurova I, Wu R, Miskolci V, et al: Increased p50/p50 NFkappaB activation in human papillomavirus type 6- or type 11induced laryngeal papilloma tissue. J Virol 76: 1533-1536, 2002.

73. Elledge RM and Allred DC: The p53 tumor suppressor gene in breast cancer. Breast Cancer Res Treat 32: 39-47, 1994.

74. Ziyaie D, Hupp TR and Thompson AM: p53 and breast cancer. Breast 9: 239-246, 2000. 